\title{
Práticas de leitura no Skoob: possíveis implicações para o ensino de literatura na escola
}

\author{
Marcos Scheffel ${ }^{\mathrm{i}}$ \\ Luiz Guilherme Barbosa ${ }^{\text {ii }}$
}

\section{RESUMO}

A crise da leitura, propalada pelo imaginário de senso comum, apresenta um ponto de contradição com as práticas de leitores em contexto digital, que têm consumido a atenção das pessoas na contemporaneidade, especialmente de crianças e jovens. Nesse sentido, a rede social de leitores Skoob, que mobiliza 5 milhões de usuários no Brasil, pode revelar práticas de leitura relevantes para considerar estratégias pedagógicas de formação de leitores no contexto da educação básica. Considerando análises críticas como as de Daniel Cassany (2011) e de Aidan Chambers (2007), este artigo apresenta e analisa práticas de leitura observadas no Skoob, e propõe diálogos entre essas práticas e o currículo da educação básica, norteado pela educação literária.

Palavras-chave: Práticas leitoras; Skoob; Formação de Leitores; Ensino de Literatura.

\begin{abstract}
The reading crisis, propagated by the commonsense imaginary, presents a point of contradiction with the practices of readers in a digital context, which have absorbed the attention of many people in contemporaneity, especially that of children and young people. In that sense, Skoob, a social network for readers which mobilizes 5 million users in Brazil, can reveal reading practices which are relevant when thinking about pedagogical strategies for training readers in the context of basic education. Considering critical analyses such as those produced by Daniel Cassany (2011) and Aidan Chambers (2007), this article presents and analyzes reading practices observed in Skoob, and proposes dialogues between such practices and the Brazilian basic education curriculum, with literary education's guidance.
\end{abstract}

Keywords: Reading practices; Skoob; Literary Education; Literature Teaching.

\footnotetext{
${ }^{i}$ Professor da Faculdade de Educação da UFRJ. Doutor em Literatura pela Universidade Federal de Santa Catarina (UFSC). | marcos.scheffel53@gmail.com

ii Professor do Colégio Pedro II - Engenho Novo. Doutor em Teoria Literária pela UFRJ.

luizguilhermebarbosa@hotmail.com
} 


\section{ANTES SE LIA MAIS...}

A falsa ideia de que antes se lia mais literatura, tema de um belo ensaio de María Teresa Andruetto (2017), gera muitas vezes um imobilismo no campo da formação de leitores na escola. Este imobilismo é gerado por uma nostalgia de um passado ideal que não retornará mais, quando os livros eram objeto de admiração, e pela impossibilidade de pôr em prática uma educação literária, já que as crianças e os jovens estariam, segundo esta perspectiva, programados para não gostarem de literatura. Logo, a escola deve despender mais tempo em leituras úteis, de gêneros do discurso da práxis social.

É certo que uma série de pesquisas apontam para um pequeno número de leitores de literatura - como a Retratos da Leitura no Brasil. ${ }^{1}$ É certo também que se entregarmos um questionário para crianças e jovens em idade escolar e perguntarmos se eles gostam de literatura teremos um resultado negativo que pode nos desestimular. ${ }^{2}$ É certo que os professores da educação básica se confrontam com o pouco interesse que as indicações de leitura geram em seus estudantes e ficam decepcionados quando constatam que as obras indicadas não foram lidas pela maioria. É certo que muitos professores da educação básica ficam decepcionados por seus alunos não reconhecerem o valor daquelas obras "inquestionáveis do cânone literário". Mas também é certo dizer que temos poucos elementos para constatar se isso tudo já não acontecia em outros tempos, pois a preocupação em se saber se as crianças e os jovens estão gostando ou não das leituras indicadas pela escola é um fato recente (COLOMER, 2007; ROUXEL, LANGLADE \& RESENDE, 2013).

No campo educacional, a preocupação de formar leitores aparece justamente quando a leitura literária tinha perdido e vinha perdendo espaço para outras formas de comunicação, entretenimento, socialização e prazer estético (HOUDART-MÉROT, 2013). Fora isso, também é esquecido que a leitura literária foi muitas vezes banida da escola ou que se liam apenas antologias recheadas de textos que cumpriam objetivos meramente pedagógicos (poemas patrióticos, lições de moral, aquisição de conhecimentos em obras paradidáticas etc.). Neste sentido é interessante a crônica de Olavo Bilac publicada em 26 de março de 1905 na Gazeta de Notícias. Nela, Bilac lamenta a notícia da morte do autor francês Jules Verne, que teria sido "o maior amigo e o maior benfeitor da nossa adolescência". Para comprovar isso, o cronista brasileiro 
recorda que, em sua época de escola, os livros de Jules Verne eram lidos em sala às escondidas, como se pode ver neste trecho:

\begin{abstract}
No colégio, todos nós líamos Júlio Verne; os livros passavam de mão em mão; e, à hora do estudo, no vasto salão de paredes nuas e tristes - enquanto o cônego dormia a sesta na sua vasta poltrona, e enquanto o bedel, que era charadista, passeava distraidamente entre as carteiras, combinando enigmas e logogrifos -, nós mergulhávamos naquele infinito sonho, e encarnávamo-nos nas personagens aventureiras que o romancista dispersava, arrebatados por uma sede insaciável de perigos e glórias, pela terra, pelos mares e pelo céu. $\mathrm{Oh}$ ! os homens e as coisas que vi, as paisagens que contemplei, os riscos que corri, os amores que tive, os sustos que curti, os combates que entrei, os hinos de vitória que cantei e as lágrimas de derrota que chorei - viajando com Júlio Verne, conduzido pela sua mão sobre-humana!

Quase morri de frio no polo, de fome numa ilha deserta, de sede na árida solidão do centro da África, de falta de ar no fundo da terra, de deslumbramento na proximidade da lua!

[...]

E, quando os meus olhos pousavam sobre a última linha de um desses romances, quando me via de novo no salão morrinho e lúgubre, quando ouvia de novo o ressonar do cônego e as passadas do bedel charadista - havia em mim aquela mesma súbita descarga de força nervosa, aquele mesmo alívio misturado de tristeza, e a que, há poucas semanas, na sala da Biblioteca Nacional vi sucumbindo o rapazola que lia a Viagem à roda da lua.

Era o regresso à triste realidade, à tábua de logaritmos, à gramática latina, à palmatória do cônego, às charadas do bedel. Era o desmoronamento dos mundos, o eclipse dos sóis, a ruína dos astros: era o pano de boca que descia sobre o palco da ilusão, matando a fantasia e ressuscitando o sofrimento... (BILAC, 2006, p. 702-705)
\end{abstract}

O contraste é nítido: as obrigações escolares feitas sob a vigilância do cônego, inclusive sob o temor de sua palmatória, versus a leitura do texto literário de Jules Verne feita à revelia das vontades da escola - texto que se abria para a imaginação, o sonho, para o prazer estético. ${ }^{3}$ Se hoje é o telefone celular objeto de proibição nas salas de aula, naquele período, pelo que se lê nessa crônica, se proibia a leitura de um livro visto como um concorrente daquilo que tinha que ser aprendido na escola. ${ }^{4}$

Fica evidente que sempre houve um desencontro entre aquilo que a escola deseja que os jovens leiam (a leitura escolar) e a leitura livre (feita fora da escola). Esta última inclusive foi incorporada como uma das formas de leitura escolar: a leitura cursiva, a leitura por prazer, a leitura de fruição - termos recorrentes desde o final dos anos 1990 nos documentos oficiais brasileiros e em discussões teóricas sobre a formação de leitores. Mas queremos aqui enfocar este contraste entre as práticas de leitura literária na escola, construídas a partir de vários quadros teórico-práticos, ${ }^{5}$ e as formas como os jovens socializam por meio da leitura e da escrita fora da escola. A posição ativa dos 
jovens que são leitores, espectadores e internautas (CANCLINI, 2008) e produtores de conteúdos - fazendo curadoria, editando, criando memes, apropriando-se de textos literários, parodiando e tantas outras práticas típicas da cultura digital. Para esta análise falaremos um pouco do Skoob - maior rede de leitores do Brasil e o que ela nos indica sobre como os jovens leem e escrevem hoje. Nosso foco é nos jovens que são leitores, pois é neles que podemos encontrar respostas para as relações que os jovens estabelecem com a leitura.

\section{O SKOOB}

Criado em 2009, o Skoob - anagrama da palavra "books" - é uma rede social onde os participantes podem partilhar suas leituras com outros usuários. Atualmente são 5 milhões de leitores ${ }^{6}$ que se valem do Skoob para: apontar os livros lidos ou abandonados, indicar as obras que agradaram ou desagradaram, escrever resenhas ou postar vídeos com comentários, interagir com outros leitores, manifestar suas preferências por escritores, citar fragmentos de obras, trocar livros etc. O Skoob pode ser usado de um computador ou em aplicativo gratuito de celular. Uma das funcionalidades disponíveis no celular é um leitor de código de barras que permite ao usuário organizar sua estante ou mesmo marcar livros desejados (por exemplo, quando está em uma biblioteca, livraria, feira do livro etc.). No perfil, o usuário pode colocar uma foto sua e tem a possibilidade de enviar mensagens privadas para outros usuários. $\mathrm{Na}$ imagem a seguir vemos a apresentação do perfil de um usuário:

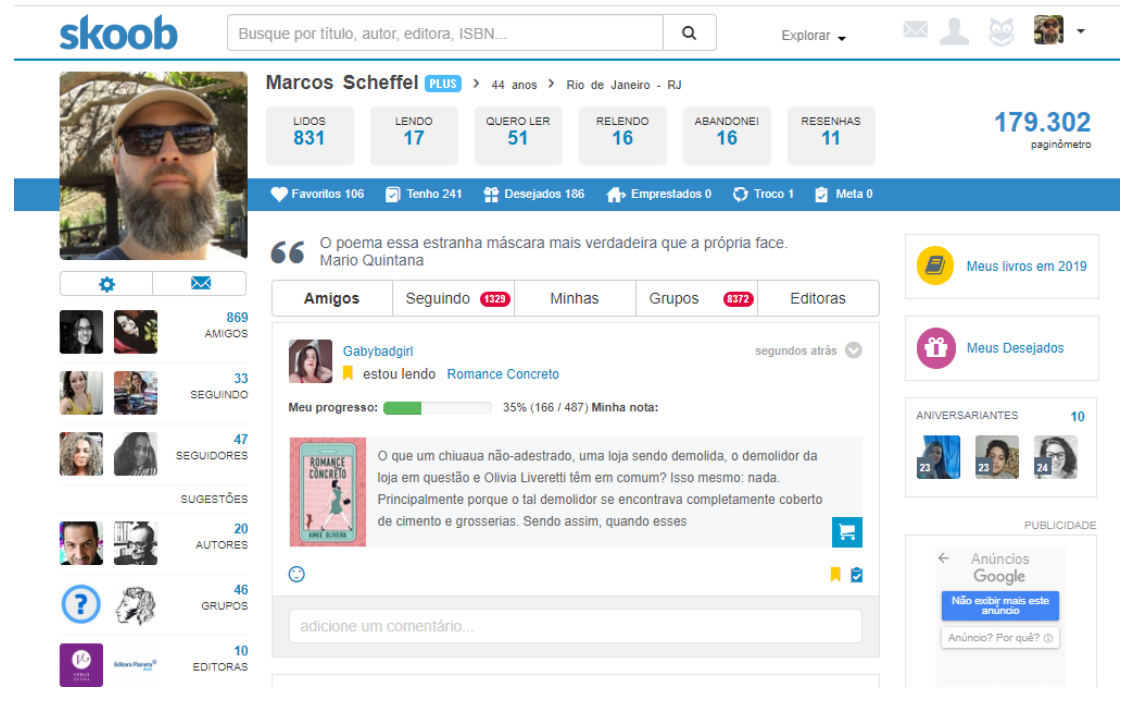


Figura 1 - Perfil de um usuário na rede social Skoob

Como se pode ver, o aplicativo permite outras funcionalidades, como saber o número de páginas lidas pelo usuário. É possível também colocar uma frase marcante para o usuário - normalmente uma citação. E o principal: o usuário tem acesso às publicações de seus amigos por meio da timeline - que pode ser trocada para publicações do próprio usuário, de editoras, de grupos. As publicações dos usuários podem ser partilhadas no Facebook e no Twitter.

Diante desse número expressivo de leitores, em sua maioria jovens leitores, que acessam esta rede de forma voluntária para praticarem atividades de escrita e leitura, ficam duas questões. A primeira ligada às práticas de leitura possíveis neste aplicativo práticas de leitura que já eram realizadas antes do advento digital, mas que aqui ganham uma visibilidade pública e que trazem consigo uma marca de autoria dos seus usuários, tirando-os da posição de meros leitores e colocando-os como produtores de conteúdos. A segunda questão se liga a como estes gestos de leitura se diferenciam dos gestos de leitura escolar e como muitos desses gestos se configuram em aprendizagens necessárias para se tornar leitor. Essas duas questões serão pensadas a partir de algumas práticas possíveis de serem realizadas com o aplicativo.

\section{INDICAR LIVROS, RECEBER INDICAÇÕES, AVALIAR E COMENTAR OBRAS LIDAS, ESCREVER SOBRE AS OBRAS LIDAS}

Aidan Chambers (2007), teórico da formação literária nas séries iniciais, propõe que é necessário criar condições para que os leitores iniciantes possam falar sobre os livros que leram. Caberia ao professor uma seleção criteriosa das obras a serem lidas em sala de aula e do tipo de perguntas a serem feitas. Para o crítico inglês, perguntas genéricas e amplas demais como o que achou da obra geram embaraços no leitor iniciante que não sabe ao certo o que responder e acaba por dar respostas curtas e que não geram uma reflexão sobre o objeto literário. Para resolver esta questão, Chambers criou um método baseado no diálogo literário e no tipo de perguntas a serem feitas para estimularem a conversação sobre livros. Uma das etapas importantes do método de 
Chambers é que os leitores iniciantes consigam compartilhar seu entusiasmo diante das obras lidas, pois, segundo ele, "só sabemos o que pensamos à medida que nos ouvimos dizendo" (CHAMBERS, 2007, p. 15). O objetivo da educação literária é para o autor inglês:

\begin{abstract}
Ajudar as crianças a participarem do drama da leitura, ajudá-los a virarem dramaturgos (reescritores do texto), diretores (intérpretes do texto), público (receptores ativos e sensíveis do texto), inclusive críticos (comentadores e explicadores e estudiosos do texto), é o que considero nosso trabalho como professores. (CHAMBERS, 2007, p. 16)
\end{abstract}

As propostas de Chambers vão ao encontro daquilo que muitos teóricos têm pensado: toda leitura é um ato de reescrita, de apropriação de um texto, de sua ressignificação. Quanto mais o jovem leitor for estimulado a isto, maior será sua chance de se envolver com o texto literário, de se tornar leitor de literatura (COLOMER, 2007; COSSON, 2016). Nesta direção, ao falarmos de um livro falamos em primeira instância para nós mesmos, num processo que nos leva a formular percepções sobre uma determinada obra. Num segundo momento, "desejamos que os outros interpretem o que dizemos e nos ajudem a entender melhor", e isto nos ajuda em nossa "capacidade de pensar" (CHAMBERS, 2007, p. 33).

Todas estas ações pensadas por Chambers acontecem de forma espontânea no Skoob. Nesta rede social, os leitores: indicam livros, recebem indicações, avaliam e comentam obras lidas e escrevem resenhas a respeito delas. Aqui cabe uma observação: qualquer comentário produzido sobre um livro é considerado uma resenha no Skoob. Ou seja: uma palavra, uma frase pode ser considerada uma resenha. Mas há espaço também para textos mais elaborados e mais analíticos sobre as obras lidas. Vejamos algumas resenhas sobre Fun Home - uma tragicomédia em família, ${ }^{8}$ da quadrinista americana Alison Bechdel, livro lançado no mercado editorial brasileiro em 2011:

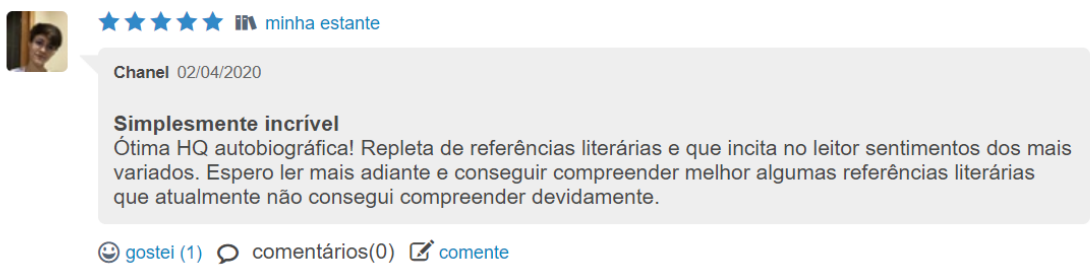

Figura 2 - Resenha sobre o livro Fun Home 


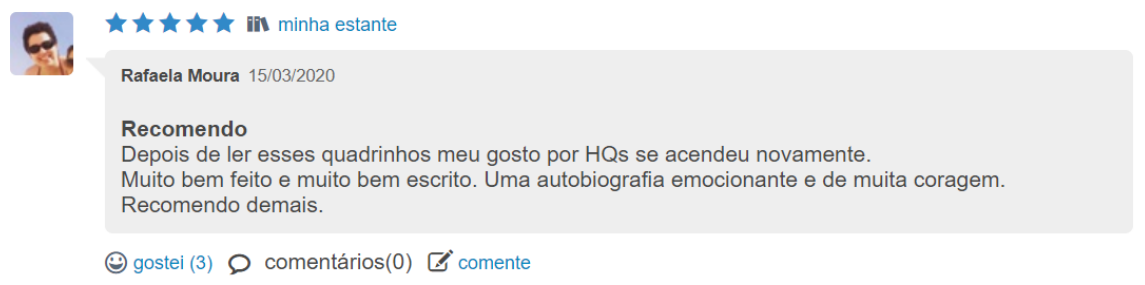

Figura 3 - Resenha sobre o livro Fun Home

Estas duas primeiras resenhas cumprem com dois dos quatro elementos que se esperam do gênero resenha, ou seja: apresentar, descrever, avaliar, recomendar ou não um livro (MOTTA-ROTH; HENDGES, 2010). O livro aqui é avaliado (por meio da nota atribuída de 1 a 5 estrelas) e recomendado (os títulos das resenham indicam isto). Há ainda aqui um certo pacto com releituras futuras da obra em momentos de maior maturidade para que seja possível entender melhor as citações literárias de que o livro está repleto. $^{9}$

A resenha da usuária Steph Mostav (Figura 4) cumpre com os elementos anteriores - avaliar e recomendar - e também apresenta e descreve a obra, produzindo um texto mais analítico. Nas resenhas lidas até aqui, percebe-se o tom bastante pessoal deste tipo de produção textual no Skoob, pois muitas vezes há uma memória afetiva da leitura do livro, uma situação de leitura, manifestada pelo uso aberto da primeira pessoa - características que também são muito usadas por resenhistas renomados. ${ }^{10}$

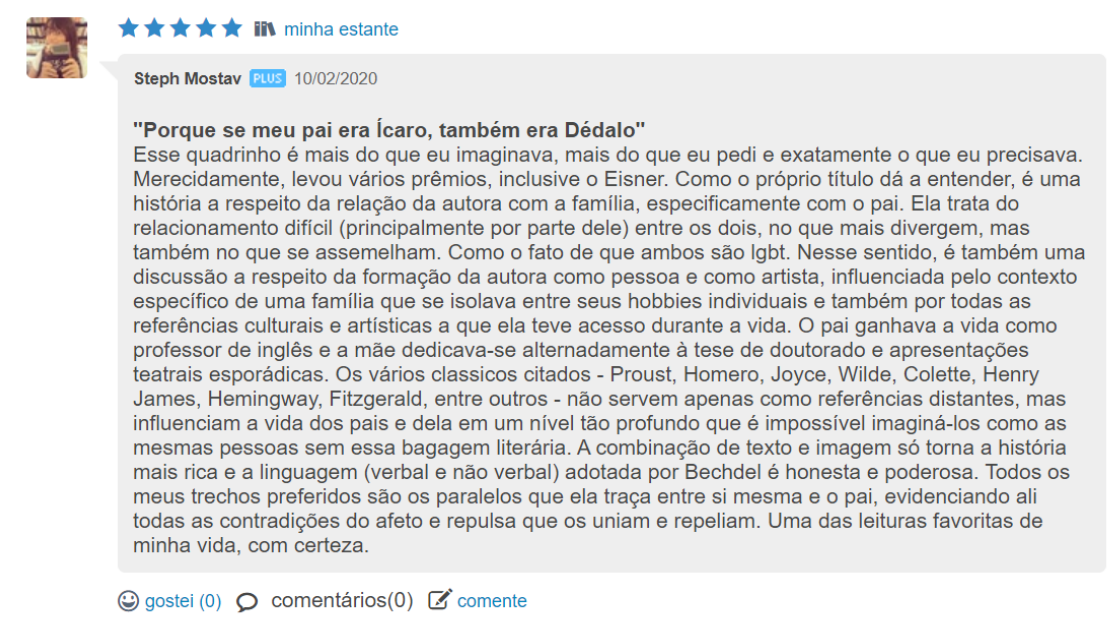

Figura 4 - Resenha da usuária Steph Mostav 
A manifestação da subjetividade do leitor tem sido um elemento extremamente valorizado por aqueles que atuam no campo da formação de leitores na escola. Como explica Annie Rouxel, a subjetividade do leitor já foi vista como algo indesejado, algo fora do texto que não deveria imergir. No entanto, com o passar do tempo, percebeu-se que esta subjetividade era desejada e que ela era capaz de ser o gatilho para leituras mais críticas (ROUXEL, 2013). Nesta comunidade de leitores, a subjetividade é quase sempre evocada ao se falar dos livros lidos - é comum que a cena de leitura, a forma como o livro chegou até as mãos do leitor, que as emoções despertadas sejam parte dos comentários. Comentários que mostram um leitor em construção ou um leitor já maduro, capaz de comparar a leitura presente com outras leituras, de articular sua própria vida com a leitura.

Já a resenha da skoober Camila faz um importante relato: o conhecimento do livro de Bechdel foi em um Clube de Leitura. Ou seja: a usuária participa de outras comunidades de leitores. Ela procura formas de conhecer novas obras e de poder trocar suas opiniões com outros leitores.

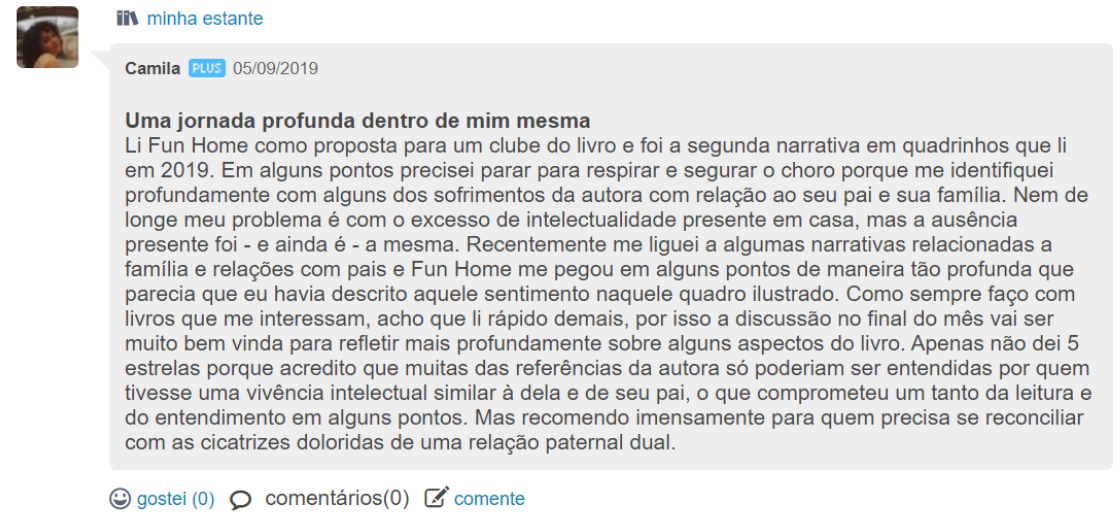

Figura 5 - Resenha da skoober Camila

O Skoob também nos fornece visões gerais sobre a leitura e a aceitação de um determinado livro, como se pode ver na página das obras de Bechdel no aplicativo (Figuras 6 e 7). 


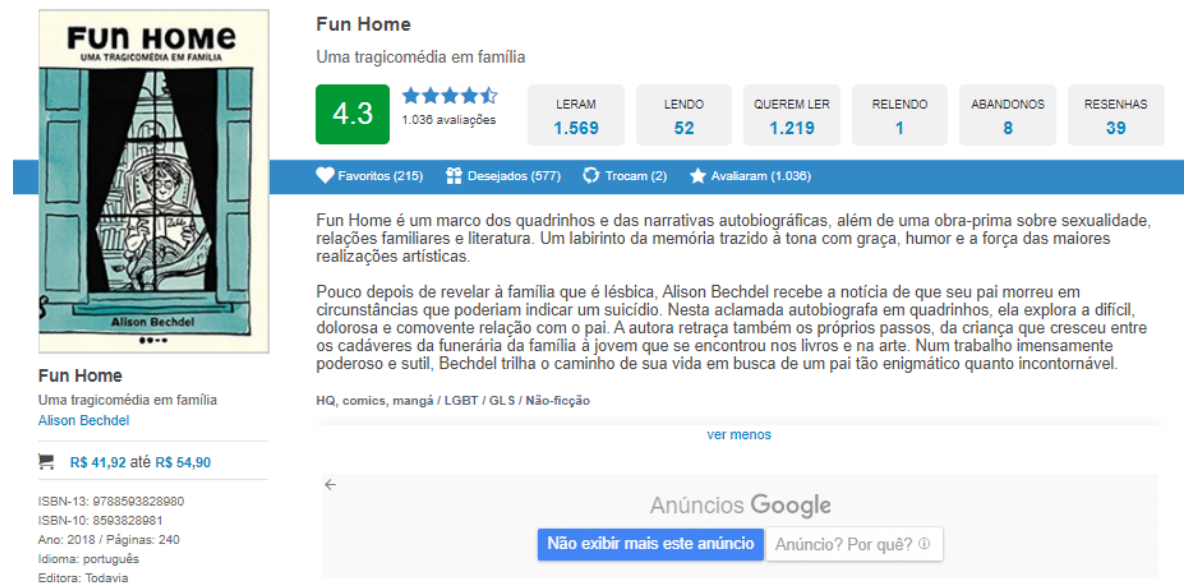

Figura 6 - Informações sobre o livro Fun Home no Skoob

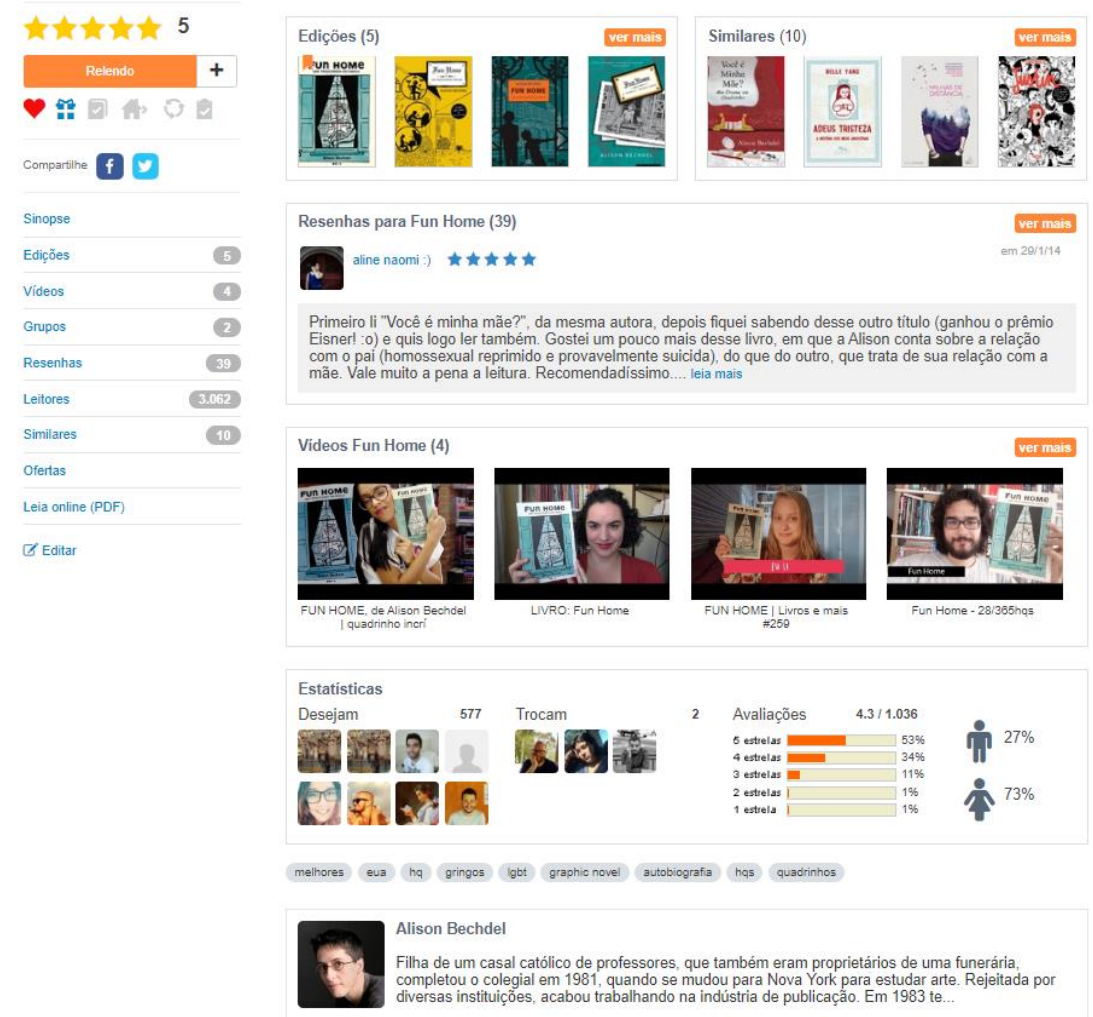

Figura 7 - Informações sobre o livro Fun Home no Skoob

Temos aí a média da nota atribuída pelos leitores (4,3 - em uma escala de 1 a 5), o número de leitores, quantos leram, quantos querem ler, quantos abandonaram e a quantidade de resenhas. Na linha abaixo desta, em azul, temos quantos leitores colocaram esta obra como favorita, desejada ou que disponibilizaram o livro para troca. Há também uma série de vídeos com comentários sobre o livro e um gráfico estatístico 
com o percentual de leitores que avaliaram a obra (em cada nota) e o número de leitores e de leitoras - saltando aos olhos a maior quantidade de mulheres leitoras.

Uma das funcionalidades importantes do Skoob é a visibilidade dada à biblioteca do usuário. Esta biblioteca é formada tanto das leituras realizadas ou dos livros que o usuário tem em sua estante física ou em formato digital. Os livros podem ser divididos por categorias que incluem: lidos, desejados, abandonados, favoritos. Há ainda uma ferramenta que permite você comparar a compatibilidade de sua biblioteca com a biblioteca de outros usuários. Os livros em comum são apontados e um percentual de compatibilidade aparece. Abaixo podemos ver o como se apresenta a comparação de duas bibliotecas - aqui com os livros semelhantes e uma taxa de compatibilidade de $12 \%$.

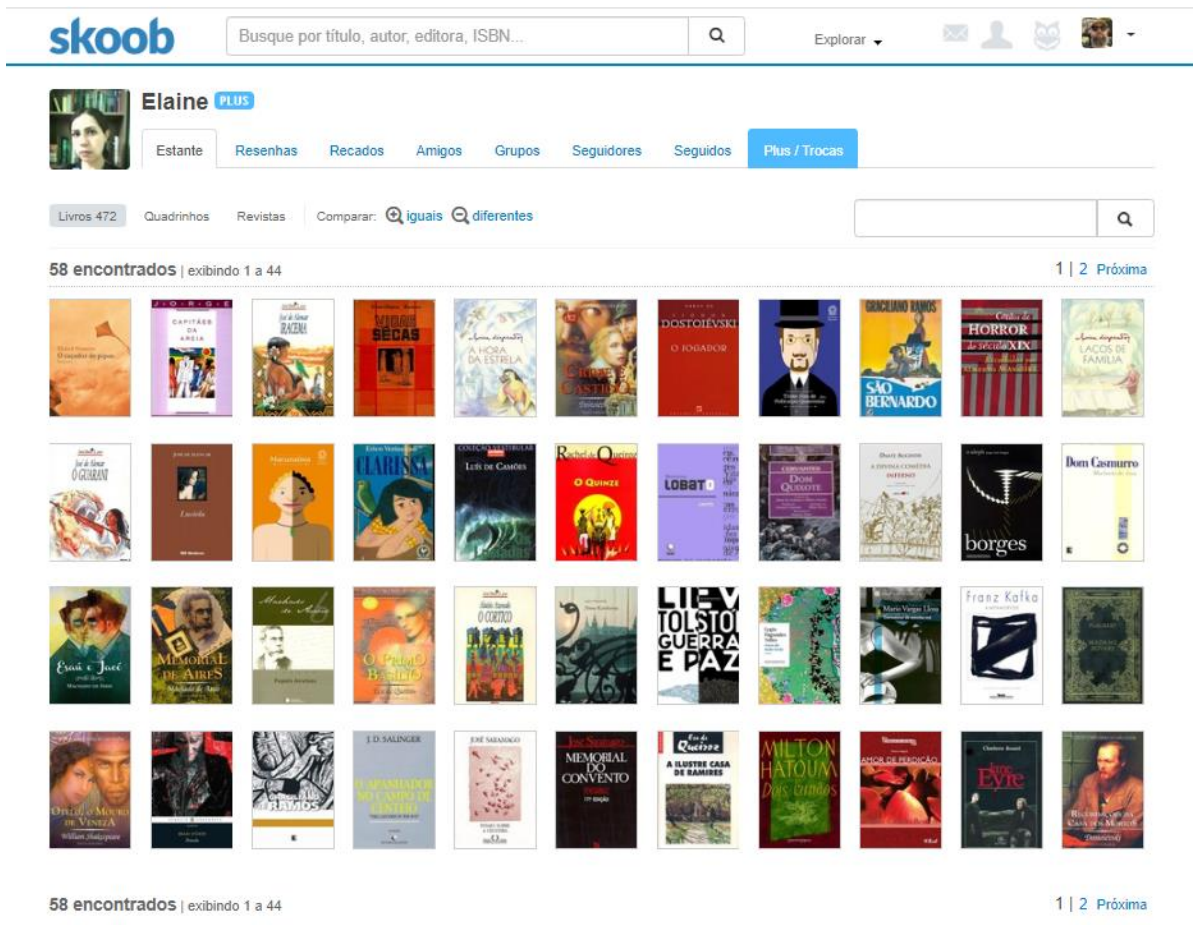

Figura 8 - Comparação da estante de dois usuários do Skoob

Os skoobers também podem trocar livros entre si. Neste caso, o usuário precisa habilitar sua conta para isto - virando um usuário "plus" - e registrar os livros que deseja trocar. A cada livro efetivamente trocado, ou seja, com envio e avaliação da troca pelo outro usuário gera-se um crédito. Este crédito pode ser usado para aquisição de obras disponibilizadas para troca por outros usuários do Brasil. 


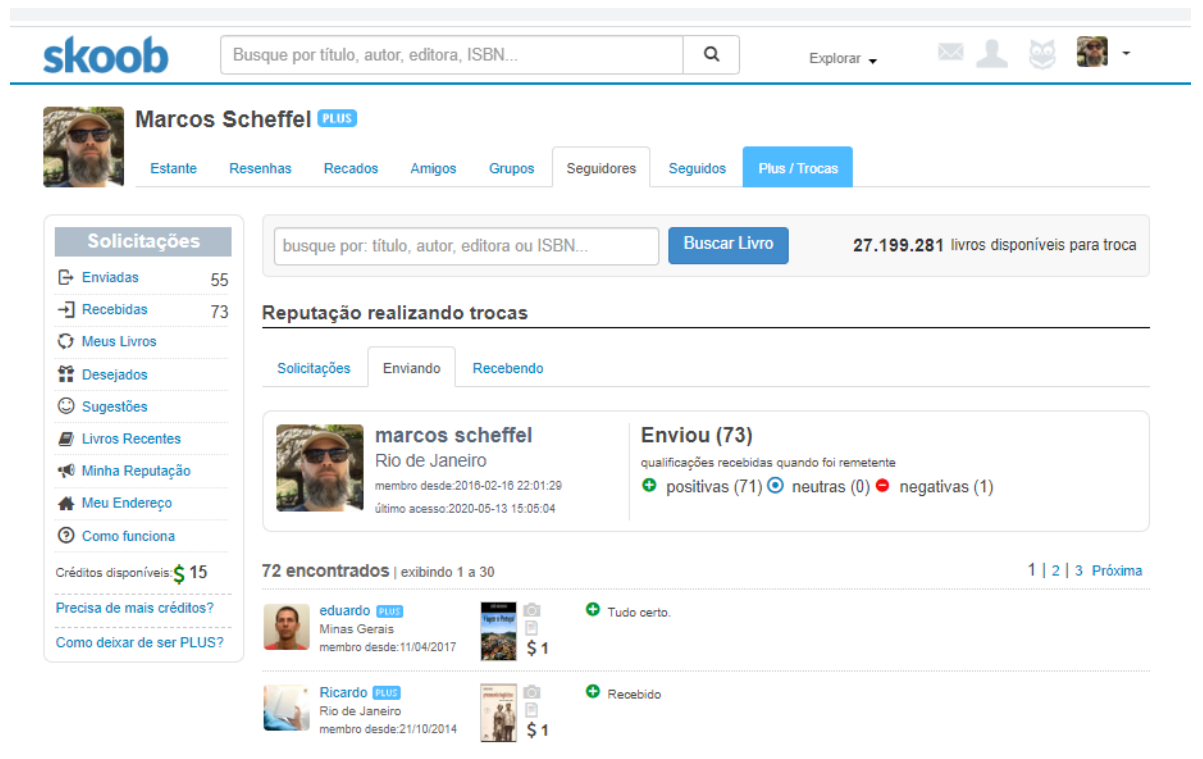

Figura 9 - Página de troca do usuário no Skoob

Na página plus do usuário, podemos ver como funciona o sistema de trocas. Podem-se ver as obras recentemente disponibilizadas para troca por outros usuários, ver se obras desejadas estão disponíveis para troca, ver sugestões de livros (que são configuradas conforme os gostos do usuário). Cada troca é avaliada e isto gera um indicativo para o usuário que pode ser consultado na barra (minha reputação). No caso deste usuário, ele realizou 73 trocas - sendo 71 positivas e 1 negativa (além de 1 ainda não avaliada). A conservação do livro, a celeridade na remessa e a rápida liberação dos créditos para troca são critérios que pesam nesta avaliação.

\section{GESTOS DE LEITURA DO SKOOB E A LITERATURA NA ESCOLA}

Os problemas da escolarização são complexos e antigos, mas não devem se tornar uma armadilha para professores e criadores do currículo escolar. Para estudantes, as práticas pedagógicas não costumam ser suficientes para garantir a aprendizagem, pois estão relacionadas com o vínculo pedagógico entre aluno e professor, aluno e colegas de turma, aluno e comunidade escolar, família e escola, assistência psicossocial e cotidiano escolar etc. No entanto, isso não significa abdicar de transformar constantemente as práticas de sala de aula, reavaliando-as a cada projeto realizado. 
A sociabilidade proporcionada por uma rede social como o Skoob provavelmente consiste num paradigma da experiência afetiva de crianças e jovens atualmente, ativos produtores textuais em Tik Tok, Twitter, Whatsapp, Medium, Instagram etc. Em que medida uma comunidade produzida entre perfis numa rede social reunidos em torno de um interesse comum pode dialogar com uma turma de escola, na qual a convivência mais ou menos conflituosa entre pessoas em formação está mediada por professores cotidianamente?

Assim, não se trata de "usar" o Skoob em sala de aula. O mais importante está em pensar como os conceitos operados nessa rede social podem revelar algo da experiência comunitária contemporânea, o que por sua vez pode aparecer na sala de aula. Por exemplo, no ensino baseado nos gêneros textuais, predominante no segundo segmento do ensino fundamental, a compreensão de que uma "resenha" pode aparecer no Skoob como um texto brevíssimo formado por uma frase, ou como um texto com marcas de memória nos cadernos de cultura (ver Nota X), ou como intervenção irônica de um estudante-leitor na sala de aula. Desloca-se, portanto, de uma concepção normativa do currículo - uma resenha deve ser escrita dessa maneira - para a concepção do currículo como práxis social, produção cotidiana em sala de aula, mediada pelo professor. Os objetivos no trabalho com a prática da resenha devem estar claros para o educador, e o conhecimento do Skoob e de sua diferença em relação às práticas canônicas de leitura são referência e recurso para o planejamento da aula e a escuta de estudantes.

Além da prática da resenha, a atribuição de notas para a leitura tem o potencial de convidar estudantes a ocupar espaço de atribuição predominante de professores. A avaliação em escala numérica pode se dar com base em critérios subjetivos, mas também pode encontrar, num debate argumentado, valores comuns que demonstrem as razões da nota atribuída. Algo de semelhante se dá no conhecimento da biblioteca e do grau de afinidade entre bibliotecas disponíveis nos perfis do Skoob. O acervo de livros em PDF ou livros físicos dos estudantes pode vir a ser explorado - por meio de fotografias, relatos, transporte de livros até a escola - como recurso que aprofunda as relações pedagógicas entre estudantes de uma turma, que se reconhecem como leitores em comunidade. 
As práticas de leitura encontradas na internet não representam um subterfúgio pedagógico. Elas são uma oportunidade de compreensão da experiência sociocultural e de crítica da rotina pedagógica na escola. Professores que, ainda que não sejam usuários de redes sociais, procuram conhecer e pesquisar práticas de produção cultural on-line podem ter acesso a um material muito rico e complexo que revela maior exigência para as práticas pedagógicas. É o que defende Cassany, considerando o caráter diverso dos textos on-line como sinal da cultura democrática que pode estar presente no espaço digital:

Hoje, a leitura digital é prática comum para muitos estudantes e será mais no futuro à medida que o acesso à rede cresce em celulares, laptops e telas digitais. Definitivamente, lemos e escrevemos de maneira diferente na Internet (Zayas, 2010), já que há mais "lixo", mais mistura de textos e mais diversidade sociocultural (Cassany, 2006), criando um ambiente ainda mais adequado para praticar a criticidade. (CASSANY, 2011, p. 31, nossa tradução)

Hoje, a internet não representa mais, como há duas décadas, um fantasma da automação do conhecimento, que teria o potencial de eliminar a escola. Um olhar contraditório para esse espaço tem a chance de reconhecer as redes sociais, especialmente aquelas em que as práticas de leitura estão evidentes, como é o caso do Skoob, como formas da experiência leitora que requerem diálogo com a sala de aula.

Considerar que a literatura carece de atenção entre a juventude em comparação com "outros tempos" em que a escola foi mais influente no imaginário cultural de crianças e adolescentes significa não apenas desconsiderar efeitos do processo de universalização do acesso à escola pública brasileira das últimas décadas, como também supor que o papel de cada professor é inócuo no ensino e na formação dos estudantes. É precisamente o poder que um professor detém de se tornar referência cultural para seus estudantes, de produzir currículo em diálogo com estudantes e a comunidade escolar e, por fim, de ler a experiência cultural em espaço digital das juventudes para dialogar com ela na sala de aula que pode movimentar a escola e tirar os professores daquele imobilismo gerado pela ideia que antes se lia mais. 


\section{Referências}

ANDRUETTO, María Teresa. Ler, direito de todos. In: ANDRUETTO, María Teresa. A leitura, outra revolução. Tradução de Newton Cunha. São Paulo: Edições SESC, 2017. p. 113-133.

BILAC, Olavo; DIMAS, Antonio. Bilac, o Jornalista. São Paulo: Imprensa Oficial do Estado de São Paulo, Editora da Universidade de São Paulo, Editora da Unicamp, 2006.

CANCLINI, Néstor García. Leitores, expectadores e internautas. Tradução Ana Goldberg. São Paulo: Iluminuras, 2008.

CASSANY, Daniel. Prácticas lectoras democratizadoras. Textos de Didáctica de la Lengua y de la Literatura, n. 58, v. 1, jul. 2011. p. 29-40.

CHAMBERS, Aidan. Dime - los niños, la lectura y la conversación. Traducción de Ana Tamarit Amieva. México: FCE, 2007.

COLOMER, Teresa. Andar entre livros: a leitura literária na escola. Tradução de Laura Sandroni. São Paulo: Global, 2007.

COSSON, Rildo. Letramento literário: teoria e prática. $2^{\mathrm{a}}$ ed. São Paulo: Contexto, 2016.

HOUDART-MÉROT, Violaine. Da crítica de admiração à leitura "scriptível". In: ROUXEL, Annie (org.). Leitura subjetiva e ensino de literatura. Tradução de Neide Resende e outros. São Paulo: Alameda, 2013, p. 103-130.

MOTTA-ROTH, Désirée; HENDGES, Graciela Rabuske. Produção textual na universidade. São Paulo: Parábola Editorial, 2010.

TAUVERON, Catherine. Direitos dos textos e direitos dos jovens leitores um equilíbrio instável. In: ROUXEL, Annie (org.). Leitura subjetiva e ensino de literatura. Tradução Neide Resende e outros. São Paulo: Alameda, 2013, p. 117-129.

Recebido em: 26/05/2020

Aceito em: 23/07/2020

\footnotetext{
${ }^{1}$ Maiores informações podem ser encontradas no site: http://prolivro.org.br/home/

${ }^{2}$ Aliás é comum este tipo de pesquisa promovida por alunos de graduação e pós-graduação. São pesquisas que propõem uma hipótese já esperada de antemão e que de certa forma condicionam as respostas negativas dos alunos. Eles mesmos já sabem o que devem responder, o que é esperado que eles respondam.
} 


\footnotetext{
${ }^{3}$ Interessante notar que o próprio Bilac produziu materiais didáticos como apostilas cívicas e poemas para serem lidos na escola (sobre família, pátria, religião, respeito aos mais velhos, as estações do ano). Bilac também traduziu As aventuras de Chico (Max and Muritz), de Wilhelm Busch, que apresentava crianças travessas e temas nada escolares.
}

${ }^{4}$ Lembro que, em minha época de estudante das séries iniciais nos anos 1980, era totalmente vedado lermos um gibi em sala de aula e que muitos professores condenavam, por exemplo, os "erros de português" do personagem Cebolinha ou do Chico Bento. Era comum gibis serem apreendidos e os alunos serem advertidos por esta prática. Tempos depois os gibis passaram a ser bem vistos e as HQ passaram inclusive a serem indicadas (muitas vezes com práticas equivocadas de uso destes gêneros em sala de aula). Os livros didáticos também passaram a ter muitas tirinhas e a trabalhar com o gênero em algumas situações.

\begin{abstract}
${ }^{5}$ Algumas dessas práticas fazem parte da tradição escolar e às vezes são repetidas sem que haja um questionamento sobre sua eficiência: a indicação de um livro único para ser lido pela turma em um semestre, os resumos, a aplicação de provas sobre as obras indicadas. Outras se articulam com reflexões do campo da formação de leitores: como a leitura cursiva, a produção de diários de leitura, a articulação do ensino de literatura com a escrita literária etc.
\end{abstract}

${ }^{6}$ A título de comparação, a maior rede de leitores do mundo - https://www.goodreads.com/ - tem 90 milhões de leitores e foi criada em 2007. Esta rede tem a maioria das funcionalidades semelhantes às do Skoob, outras próprias dela (como os usuários poderem publicar fotos em locais de leitura - bibliotecas, livrarias etc.) e não tem outras opções do Skoob (como a troca de livro entre usuários).

${ }^{7}$ Tradução minha do espanhol do livro Dime - Los niños, la lectura y la conversación, em inglês: Tell me: children, reading and talking. É interessante notar que, na tradução para o espanhol, o título não inclui a importância da escrita a partir das leituras realizadas.

${ }^{8}$ Cito este livro, pois só tomei conhecimento desta obra de Alyson Bechdel por conta do Skoob. Sem ele, muito dificilmente conheceria a autora. Nesta direção, o Skoob me parece um ótimo lugar para os professores ampliarem seu repertório de leitura e conhecerem obras bem avaliadas por jovens leitores, que são sua maioria no aplicativo.

${ }^{9}$ Os usuários do Skoob aqui citados permitiram a publicação de suas resenhas, comentários e avaliações de obras.

${ }^{10}$ Lembro-me aqui de uma resenha sobre o livro Todas as crônicas, de Clarice Lispector - publicada na Revista Quatro Cinco Um - em que Eucanaã Ferraz evoca suas recordações de leitor das crônicas de Clarice Lispector décadas atrás. 